\title{
Load-carrying behaviour of interrupted statically indeterminate reinforced laminated glass beams
}

\author{
Kenny Martens · Robby Caspeele · Jan Belis
}

Received: 21 December 2015 / Accepted: 19 March 2016 / Published online: 1 April 2016

(C) Springer International Publishing Switzerland 2016

\begin{abstract}
There is a trend for increasing the scale of structural glass components, which is possible e.g. due to industrial investments in ever larger autoclaves. As a result, load-bearing glass beams will increasingly be incorporated in more complex structural systems. Most important, these beams are required to provide structural safety both on an element level (the beam itself) and system level (a part of, or the whole structure). Past research has resulted in a multitude of possible hybrid glass beams which provide element safety when applied with statically determinate support conditions. In particular, the stainless steel reinforced glass beam has proved to be a promising concept. Moreover, the authors performed a test programme which proved the feasibility of applying the latter beams in statically indeterminate systems. However, due to production, transportation and on-site manoeuvrability limits, safe butt connections will be inevitable for the creation of large-scale beam systems. Currently, no transparent and safe connection detailing is available. As a result, a research project was initiated to develop a connection prototype making use of the beam's reinforcement sections. This paper presents experimental test results
\end{abstract}

K. Martens $(\varangle) \cdot$ R. Caspeele $\cdot$ J. Belis

Ghent University, Technologiepark Zwijnaarde 904,

9052 Zwijnaarde, Belgium

e-mail: Kenny.Martens@UGent.be

R. Caspeele

e-mail: Robby.Caspeele@UGent.be

J. Belis

e-mail: Jan.Belis@UGent.be of statically indeterminate five-point bending tests on reinforced laminated glass beams in which the glass section is interrupted at the central support. It was concluded that these hypothetical 'connected' beams provide safe load-carrying behaviour in all cases.

Keywords Reinforced glass beams · Statically indeterminate Interrupted glass section .

Experiments $\cdot$ Safe failure behaviour

\section{Introduction}

A lot of hybrid structural glass beam concepts have been developed and tested. In these concepts, glass is combined with other, sometimes ductile, materials to create beams with satisfying load-carrying behaviour characterized by significant post-fracture strength and ductility. The latest developed concepts prove to be very promising as clarified in the overview by Martens et al. (2015a,b). One of the most promising and extensively tested concepts is the reinforced laminated glass beam. Similar to the principle of reinforced concrete, a stainless steel reinforcement section is added at the tensile edge of the beam section, in this case bonded to the laminated glass web by means of SentryGlas ${ }^{\circledR}$ (SG) interlayers. The concept was tested for statically determinate support conditions by Louter et al. (2012a,b) and later, the feasibility of applying this concept in statically indeterminate beam systems was tested by the authors of this paper. A second reinforcement sec- 
tion was added to the beam laminate creating a twosided reinforced laminated glass beam. Statically indeterminate five-point bending tests were performed on these beams, varying the reinforcement percentage and test temperature. It was concluded that all beams provided safe load-carrying behaviour in all test cases and hence the feasibility of statically indeterminate glass beam systems was proven (Martens et al. under review). The same test setup was used for the experimental test results presented in this paper. Only few statically indeterminate tests were performed on hybrid glass beams. To the author's knowledge, only one other concept using GFRP as composing material was tested in fivepoint bending (Valarinho et al. 2013). The beam section was I-shaped in which the web was made of glass and the flanges of GFRP. The bond between glass and GFRP was realized using three adhesives with different stiffness. The beams illustrated safe load-carrying behaviour characterized by significant post-fracture strength and ductility. However, as GFRP is a brittle material, the post-fracture phase was semi-ductile characterised by evolving fractures, rather than ductile resulting from reinforcement yielding. It was also concluded that the load-carrying behaviour was dependent on the stiffness of the adhesive.

Although the glass industry is investing in infrastructure to produce ever larger glass components (e.g. autoclaves,), transportation and on-site manoeuvrability will always limit the component's maximum size. Furthermore, the production of larger glass panes (larger than $6 \mathrm{~m}$ ) is not standard which sensitively increases the cost of such panes, as the continuous production process is altered. One option is to build large-span glass beams by combining normal size glass panes into a laminate (so-called splice laminated glass beams (Louter and Veer 2007; Ringli and Vogel 2016). With this technique a $21 \mathrm{~m}$ long beam was built (Trösch and Kassnel-Henneberg 2014). An important parameter for this type of beams is the glass pane configuration, as every joint in one layer should be overlapped by a glass pane in another layer. In principle, this type of beam could be produced on the building site (to solve the transportation and on-site manoeuvrability issue). However, a very clean environment is required for the lamination process (or gluing) and regarding the large surfaces to be laminated, this proposition seams unfeasible.

As a result, beam butt connections will be inevitable. Next to transparency, the most important feature of such a connection is robustness, i.e. the connection has to contribute to the overall system safety, also after glass breakage. Currently applied butt connections are mechanical ones in which steel plates, connected to the glass beams using bolts, are used to bridge the gap between the beams (Fig. 1a). However, such connection is not transparent and the bolts lead to unwanted stress concentrations in the glass.

To solve the latter problem, in literature attempts have been made to make connections without drilling holes in the glass. A first class of investigations was focused on the possibility of embedding a connection steel plate into the glass laminate of the beam. Two beam units could then be joined on-site by connecting both steel plates by means of a bolted or welded system (Fig. 1b). The load-transfer behaviour between embedded steel plates and glass laminates was investigated by Carvalho et al. (2011), Puller (2012), Puller and Sobek (2012), Santarsiero et al. (2013) and Santarsiero and Louter (2015). It was concluded that a significant load could be transferred through this type of connections. However, its magnitude and the stiffness of the system is highly dependent on temperature and loading rate. The load is transferred both over the embedded surface area and at the insert end. Subsequently, Puller (2012) structurally optimised the geometry of the embedded end to minimise stress concentrations. The resulting geometry had a finger-like shape. Subsequently, Carvalho et al. (2013) tested butt connected beams realizing the connection by bolting embedded perforated steel plates and using polycarbonate blocks to maintain contact between the glass panes. The connected beam system was tested through four-point bending at three different temperatures. It was concluded that ductile failure of the connection was achieved at room temperature. However, at larger temperatures, this satisfying failure mechanism did not occur. Instead, glass fracture was observed as a result of stress concentration close to the border of the embedded plate. The higher the temperature, the larger the stress concentration was. The tests at $70^{\circ} \mathrm{C}$ yielded half of the connection resistance observed at 23 and $45^{\circ} \mathrm{C}$. In addition, significant delamination was detected. Despite the beneficial avoidance of bolting and the slightly increased transparency, stress concentrations are still possible and a safe failure behaviour is not guaranteed as the load-carrying mechanism relies entirely on the interlayer, which poorly resists high temperatures. 


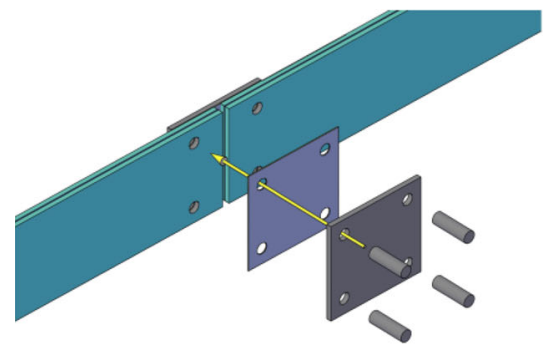

(a)

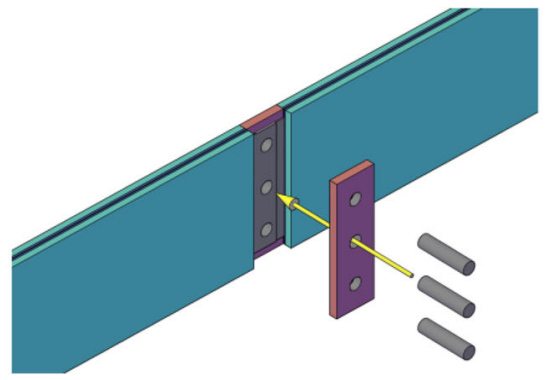

(b)

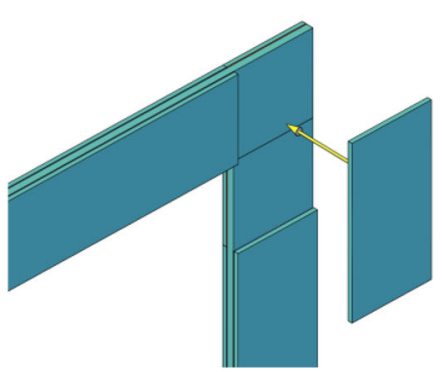

(c)

Fig. 1 Schematic representation of existing and tested connection alternatives: a bolted, $\mathbf{b}$ embedded, $\mathbf{c}$ glued connection

Another connection concept is to use a glued connection. Multi-layer glass beams are connected by recessing the outer glass panes in longitudinal direction at the connection ends. The beams are placed in such a way that the inner glass panes make contact after which two connection panels are placed in the outer voids using a transparent glue (Fig. 1c). In this way, the seam is located behind the connection panels. Nijsse (2004) applied this concept to create a connection between a vertical glass fin and a horizontal glass beam in a conservatory in Leiden, The Netherlands. Ten years later, a similar concept was investigated by Snijder et al. (2014) who designed and tested a glass portal frame spanning $8 \mathrm{~m}$. The columns and beams were made of reinforced laminated glass using Polyvinyl butyral (PVB). The connection was made by sliding the column in between the two beam members. A stainless steel saddle was used to keep the members in position. The frame was tested by performing a four-point bending test on the beam. It was concluded that the portal frame did not behave as expected as the redundancy factor until glass failure was much lower than expected. Furthermore, ultimate collapse did not occur due to reinforcement yielding, but due to lateral buckling and bond failure of the glass-to-reinforcement bond. With the glued connection, transparency is maximised (at least when no steel saddle is used). However, as was the case for the embedded connection, the loadtransfer mechanism in the connection heavily relies on the adhesive. In addition, the connection itself will not fail in a ductile way. In the current paper, a hypothetical butt connection between two reinforced glass beams is experimentally tested. The beams are continuous except at the central support where the glass panes are interrupted. This way, it is possible to investigate
Table 1 Material properties for ANG and SG

\begin{tabular}{lll}
\hline Material & $\begin{array}{l}\text { Annealed } \\
\text { float glass }\end{array}$ & SentryGlas ${ }^{\circledR}$ \\
\hline Young's modulus $(\mathrm{MPa})$ & 70,000 & $110.53 / 12.17 * *$ \\
Yield strength $(\mathrm{MPa})$ & $\mathrm{n} / \mathrm{a}$ & $\mathrm{n} / \mathrm{a}$ \\
Tensile strength $(\mathrm{MPa})$ & $45^{*}$ & 34.5 \\
Elongation at fracture $(\%)$ & $\mathrm{n} / \mathrm{a}$ & 400 \\
Poisson ratio $(-)$ & 0.20 & $0.49 / 0.50 * *$ \\
Density $\left(\mathrm{kg} / \mathrm{m}^{3}\right)$ & 2500 & 950 \\
Glass transition & $\mathrm{n} / \mathrm{a}$ & 55 \\
temperature $\left({ }^{\circ} \mathrm{C}\right)$ & &
\end{tabular}

* This is a characteristic value. In reality, the strength of glass is variable due to the effect of surface flaws,

** These values were obtained from Callewaert (2012) for a temperature of $23 / 60^{\circ} \mathrm{C}$ and a load duration of $30 \mathrm{~min}$

the load-carrying behaviour of a beam in which only the reinforcement is 'connected'. Furthermore, load redistribution is evaluated between the weaker central section and the full-strength mid-span sections. A similar setup was used to create a $8 \mathrm{~m}$ long box aquarium (Veer et al. 2003)

\section{Materials and methods}

The tested glass beams are made of annealed float glass (ANG) panes and stainless steel EN1.4301 reinforcement sections, laminated using a SentryGlas ${ }^{\circledR}$. interlayer (SG). Table 1 summarizes the most important mechanical properties for ANG and SG. The mechanical properties of stainless steel were experimentally determined and presented in the following section. 
Fig. 2 Stainless steel uniaxial test specimens: a $10 \mathrm{~mm} \times 10 \mathrm{~mm}$ solid section and $\mathbf{b} 10 \mathrm{~mm} \times$ $10 \mathrm{~mm} \times 1 \mathrm{~mm}$ hollow profile section

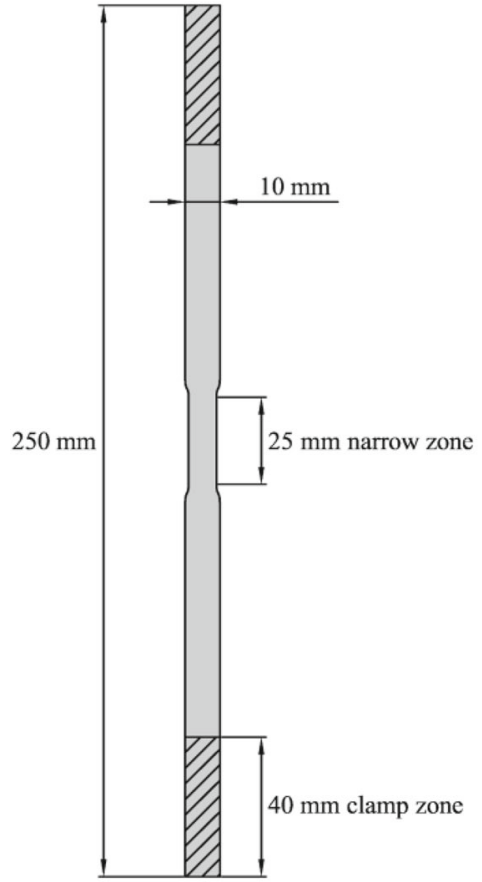

(a)

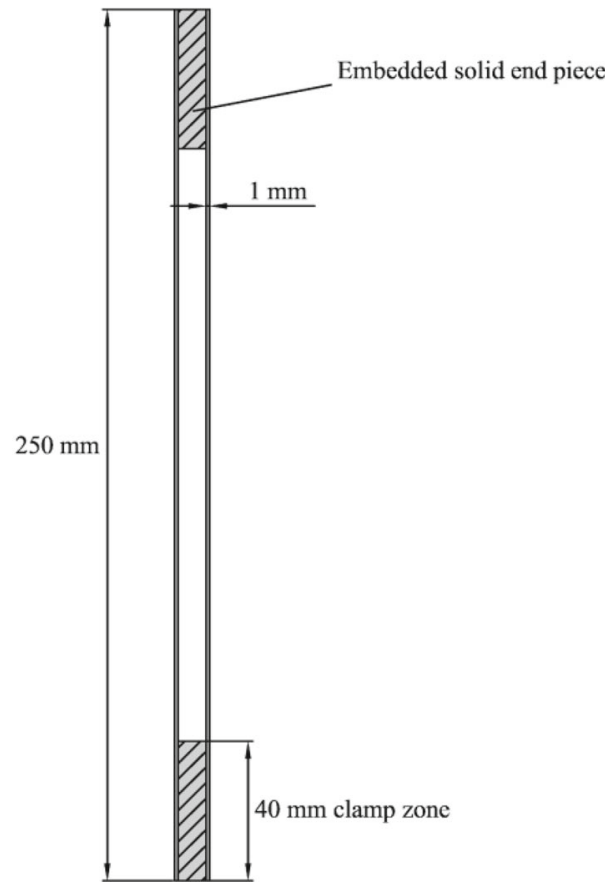

(b)

\subsection{Uniaxial tensile tests on stainless steel sections}

Two reinforcement sections were used to build the beams: a $10 \mathrm{~mm} \times 10 \mathrm{~mm}$ solid section and a $10 \mathrm{~mm}$ $\times 10 \mathrm{~mm} \times 1 \mathrm{~mm}$ hollow profile section. To perform uniaxial tensile tests, $250 \mathrm{~mm}$ long specimens were produced as illustrated in Fig. 2. The solid specimens were narrowed over a limited length to concentrate the failure zone. For the hollow profile specimens, two solid end pieces were inserted so that the specimens were easy to clamp into the test rig. Moreover, by doing this, the specimens cannot fail at the clamps. The tests were conducted on a standard $100 \mathrm{kN}$ Instron test rig, which measured the load and elongation of the test specimen. The strain was independently recorded by applying strain gauges on the test specimens. Prior to testing, all test specimens were thoroughly measured. 6 specimens were tested for each type of reinforcement, giving a total of 12 test specimens.

\subsection{Statically indeterminate five-point bending tests}

The two beam sections are displayed in Fig. 3. Typically, a $10 \mathrm{~mm}$ glass pane with reduced height is placed between two SG-interlayer sheets and two $6 \mathrm{~mm}$ glass panes. At the top and bottom of the central glass pane, two reinforcement sections are added. The specimens were $3 \mathrm{~m}$ long and built of two $1.5 \mathrm{~m}$ glass panes, creating a seam at the beam's centre. The reinforcement sections and SG-interlayer were continued over the seam and had a length of $3 \mathrm{~m}$. During the production process, the glass panes were placed in contact at the seam. However, as the SG-interlayer is fluid during autoclaving, the seam was filled with SG. In this way, a beam was realized as if it was connected primarily through its reinforcement sections, and secondarily, its interlayer. A total of 12 specimens were produced and subdivided into four test series as the effect of temperature was also investigated (next to the effect of reinforcement percentage). Table 2 gives an overview of all test specimens and test parameters.

The beams were tested in statically indeterminate five-point bending, with two spans of $1450 \mathrm{~mm}$, a load span of $1450 \mathrm{~mm}$ and a lateral support span of $1000 \mathrm{~mm}$ (see Fig. 4). At the centre, an extra lateral support was added as the beams had an initial lateral deformation as a consequence from production. In this way, local buckling effects are avoided. Furthermore, a $5 \mathrm{~mm}$ thick rubber sheet was placed between the beam's edge and the 

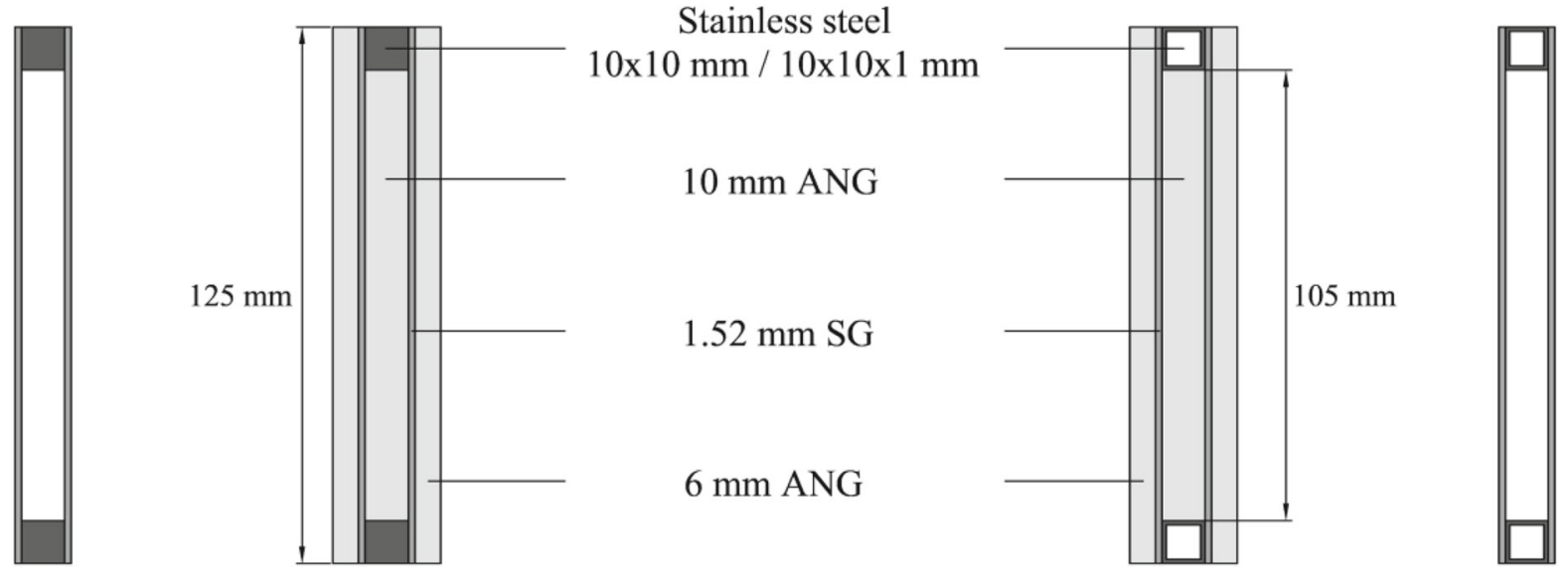

Fig. 3 Schematic representation of the produced beam sections (left central and full section of solid reinforced beam, right full and central section of hollow profile reinforced beam)

Table 2 Overview of test specimens $(\mathrm{S}=$ solid reinforcement, $\mathrm{H}$ = hollow profile reinforcement)

\begin{tabular}{llll}
\hline Test series & Reinforcement & Temperature & $\begin{array}{c}\text { Number of } \\
\text { specimens }\end{array}$ \\
\hline S-23 & $10 \mathrm{~mm} \times 10 \mathrm{~mm}$ & 23 & 3 \\
S-60 & $10 \mathrm{~mm} \times 10 \mathrm{~mm}$ & 60 & 3 \\
$\mathrm{H}-23$ & $10 \mathrm{~mm} \times 10 \mathrm{~mm} \times 1 \mathrm{~mm}$ & 23 & 3 \\
$\mathrm{H}-60$ & $10 \mathrm{~mm} \times 10 \mathrm{~mm} \times 1 \mathrm{~mm}$ & 60 & 3 \\
\hline
\end{tabular}

steel support to create a less stiff support than the two outer ones. This has an important effect on the bending moment line, creating a higher moment value at the span zones at the time of initial glass fracture. Pictures of the test setup are provided in Fig. 5. The tests were executed displacement-controlled with a constant rate of $0.1 \mathrm{~mm} / \mathrm{s}$. The displacement was imposed using a $100 \mathrm{kN}$ single-acting hydraulic jack on which a loading beam was mounted to create two loading points. The total and central support load were recorded using load cells. Vertical support deformations and both mid-span deflections were measured using Linear Variable Differential Transformers (LVDT's). Furthermore, strain gauges were applied on the outer glass panels and reinforcement sections at the critical glass zones (both midspans and central support zone) to record the strains. More information concerning the test setup can be found in Martens et al. (under review).

Also the effect of higher temperature was assessed in this investigation. Therefore, the beam specimens were preconditioned and tested in a climatic chamber at 23 and $60^{\circ} \mathrm{C}$ and $55 \%$ relative humidity. The preconditioning lasted a week for $23^{\circ} \mathrm{C}$ and $48 \mathrm{~h}$ for $60^{\circ} \mathrm{C}$ after which the specimens were tested.

\section{Results and discussion}

\subsection{Uniaxial tensile tests on stainless steel}

The resulting stress-strain diagrams are presented in Fig. 6 for both types of reinforcement. As the extension of the test specimens was larger than the extension limit for the strain gauges, the load-extension curves are added for completeness. The assessed mechanical properties are listed in Table 3. Looking at the loaddisplacement diagrams, it is stated that the reinforcement exhibits a bilinear behaviour with strain hardening. Failure occurred more gradually for the solid sections compared to the other ones. The hollow profile sections illustrate higher stiffness as well as higher yield and tensile strength values. However, the section is less ductile. These observations are explained by the production process of the hollow profile sections, which makes them stiffer and gives them larger strength values. It is further concluded that both stainless steel sections reach high yield and tensile strength values, as well as high ductility, compared to regular steel. As a result, the post-fracture capacity of glass beams reinforced with stainless steel is expected 
Fig. 4 Schematic

representation of the test setup and beam specimens

Fig. 5 Pictures of the test setup: a overview, b outer support and central support
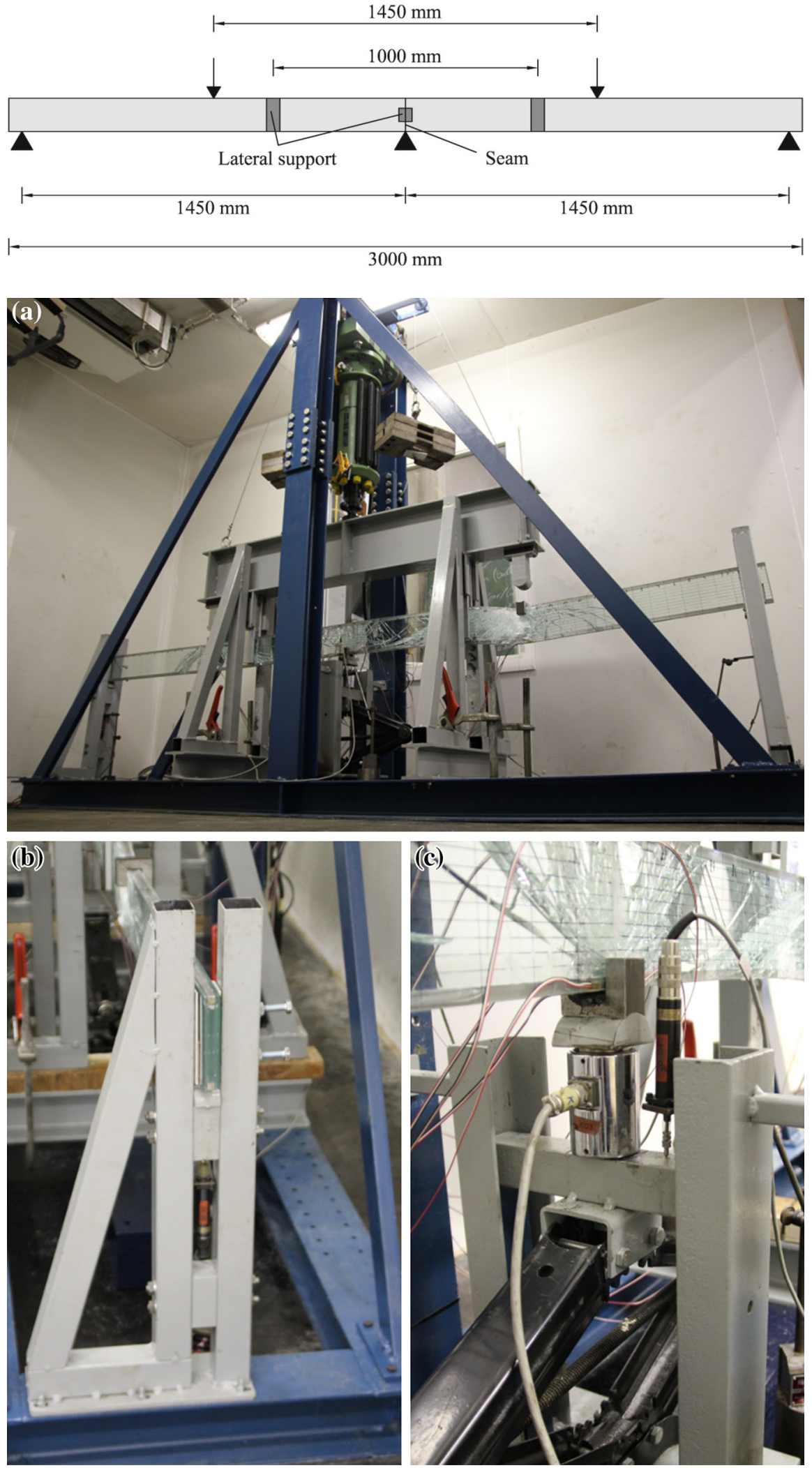

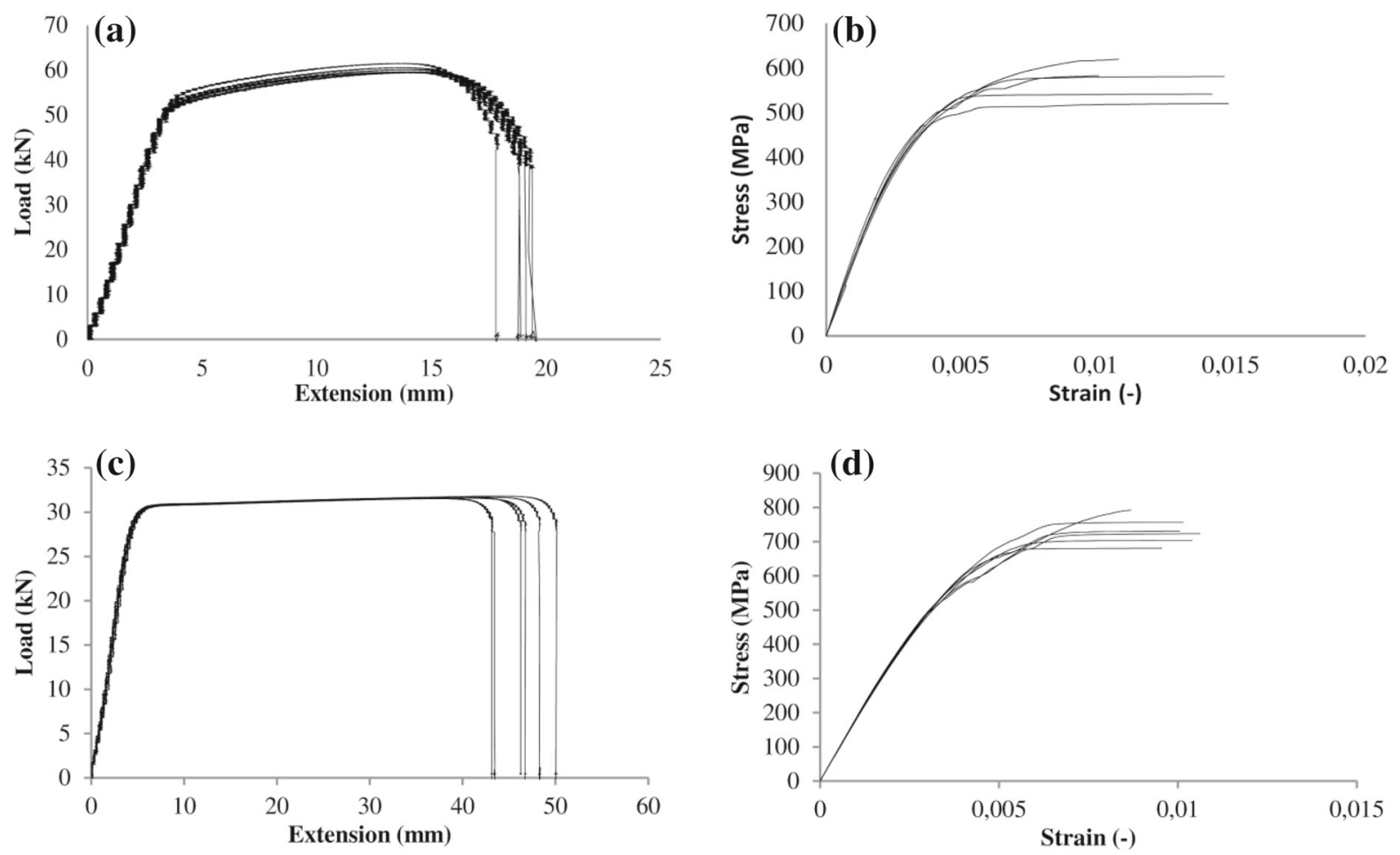

Fig. 6 Uniaxial tensile test results: a Load-displacement diagram and b engineering stress-strain diagram for $10 \mathrm{~mm} \times 10 \mathrm{~mm}$ solid section; c Load-displacement diagram and d stress-strain diagram for $10 \mathrm{~mm} \times 10 \mathrm{~mm} \times 1 \mathrm{~mm}$ hollow profile section

Table 3 Mechanical properties for stainless steel

\begin{tabular}{lcc}
\hline Reinforcement type & $\begin{array}{l}10 \mathrm{~mm} \times \\
10 \mathrm{~mm}\end{array}$ & $\begin{array}{l}10 \mathrm{~mm} \times \\
10 \mathrm{~mm} \times 1 \mathrm{~mm}\end{array}$ \\
\hline Young's modulus (GPa) & 178.4445 & 182.249 \\
$0.2 \%$ Yield strength $(\mathrm{MPa})$ & 530.5 & 701.9 \\
Yield strain (-) & 0.0050 & 0.0059 \\
Tensile strength (MPa) & 760.1 & 929.3 \\
Strain at tensile strength (-) & 0.5566 & 0.2365 \\
\hline
\end{tabular}

to be higher than for those reinforced with regular steel.

\subsection{Statically indeterminate five-point bending tests}

In this section, an overview of the experimental bending results is presented. Firstly, the overall load-carrying behaviour of the beams is given by evaluating their load-displacement diagrams. Secondly, the effects of reinforcement percentage and temperature on the behaviour will be evaluated. Focus is laid on the central support zone, where the seam is located.

Figure 7 summarizes all load-displacement curves for the solid $(\mathrm{S})$ and hollow profile $(\mathrm{H})$ reinforced beam specimens, tested at 23 and $60^{\circ} \mathrm{C}$. For these curves, the average mid-span deflection was calculated. After failure of one of the span zones, the curve was stopped as no significant average value could be calculated anymore. However, the end of the current curves corresponds to ultimate collapse of the beams. It is stated nevertheless that all beams illustrated a residual phase after collapse, driven by load redistribution, with a load capacity smaller (but significant) than the maximum achieved load. In what follows, reference names will be used for the different tests in the form 'reinforcement-temperature' (as in Table 2). Important strength values (i.e. the initial failure load, ultimate capacity and post-fracture performance) along with some statistics and qualitative information are given in Table 4. 


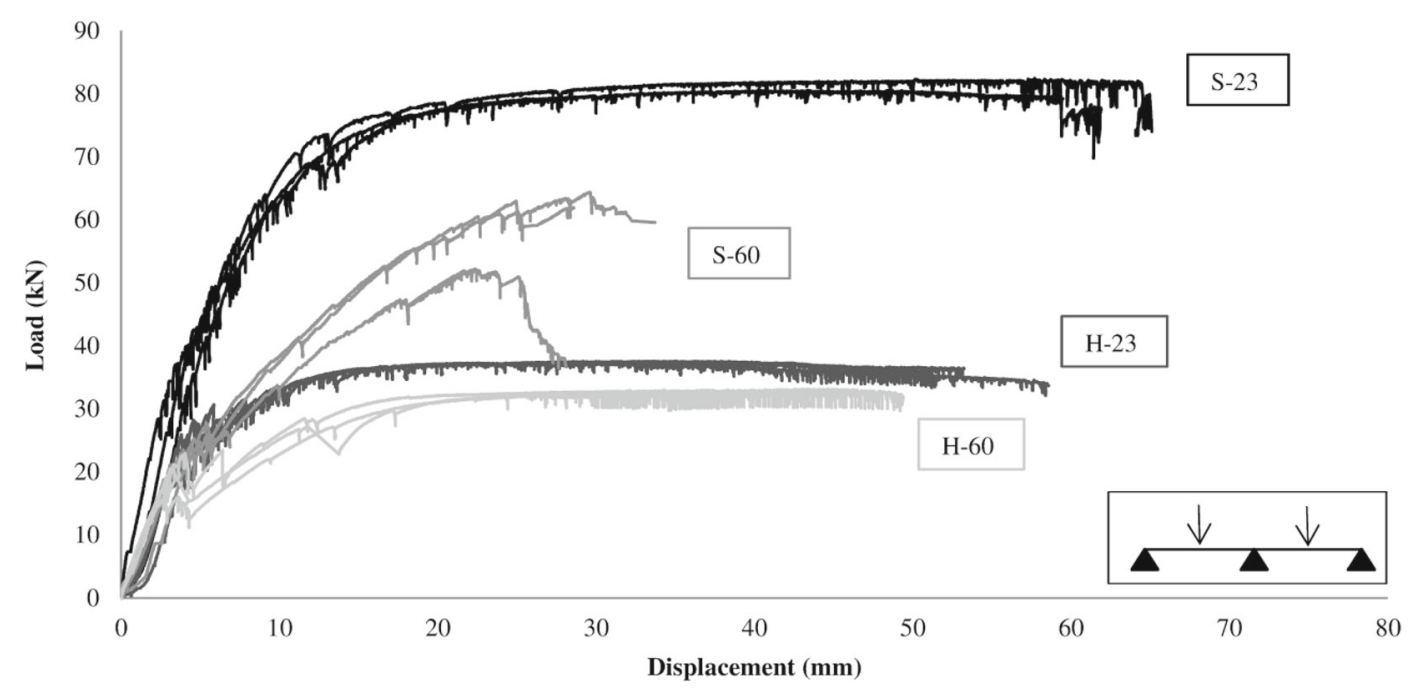

Fig. 7 Load-displacement diagrams of the tested beam specimens ('S' = solid; ' $\mathrm{H}$ ' = hollow profile; ' $23^{\prime}=23^{\circ} \mathrm{C}$; ' 60 ' = $60{ }^{\circ} \mathrm{C}$ )

Table 4 Relevant information regarding the load-carrying behaviour of the beam specimens

\begin{tabular}{|c|c|c|c|c|}
\hline Series & S-23 & H-23 & S-60 & $\mathrm{H}-60$ \\
\hline \multicolumn{5}{|l|}{ Initial failure load } \\
\hline Average $(\mathrm{kN})$ & 21.83 & 15.86 & 17.31 & 17.16 \\
\hline Standard Deviation $(\mathrm{kN})$ & 4.52 & 2.15 & 1.47 & 1.77 \\
\hline $\mathrm{COV}^{* * * * *}(\%)$ & 20.73 & 13.57 & 8.50 & 10.29 \\
\hline \multicolumn{5}{|l|}{ Ultimate capacity } \\
\hline Average $(\mathrm{kN})$ & 80.81 & 37.40 & 60.23 & 32.87 \\
\hline Standard deviation $(\mathrm{kN})$ & 1.58 & 0.16 & 6.98 & 0.29 \\
\hline $\operatorname{COV}(\%)$ & 1.95 & 0.44 & 11.58 & 0.87 \\
\hline \multicolumn{5}{|l|}{ Post-fracture performance* } \\
\hline Average $(-)$ & 3.81 & 2.39 & 3.50 & 1.93 \\
\hline Standard deviation $(-)$ & 0.75 & 0.36 & 0.53 & 0.21 \\
\hline $\operatorname{COV}(\%)$ & 19.68 & 15.16 & 15.22 & 10.65 \\
\hline Plastic phase & Yes & Yes & No & Yes \\
\hline Reinforcement slip & No & No & Yes & No \\
\hline \multicolumn{5}{|c|}{ Primary collapse mechanism** } \\
\hline & $\begin{array}{l}\text { Compressive } \\
\text { glass failure }\end{array}$ & $\begin{array}{l}\text { Reinforcement } \\
\text { rupture }\end{array}$ & $\begin{array}{l}\text { Compressive } \\
\text { glass failure }\end{array}$ & $\begin{array}{l}\text { Reinforcement } \\
\text { rupture }\end{array}$ \\
\hline \multicolumn{5}{|l|}{ Final collapse mechanism $* * *$} \\
\hline & $\begin{array}{l}\text { Lateral buckling of } \\
\text { collapsed section }\end{array}$ & $\begin{array}{l}\text { 2nd reinforcement } \\
\text { rupture }\end{array}$ & $\begin{array}{l}\text { Lateral buckling of } \\
\text { collapse section }\end{array}$ & $\begin{array}{l}\text { 2nd reinforcement } \\
\text { rupture }\end{array}$ \\
\hline
\end{tabular}

* The post-fracture performance is calculated as the ultimate capacity divided by the initial failure load

** This is the first collapse mechanism, occurring at the end of the load-displacement curves in Fig. 7

*** This is the final collapse mechanism occurring at the end of the residual phase (not depicted in Fig. 7). After this phase, the beam has completely collapsed

$* * * * \mathrm{COV}=$ coefficient of variation 

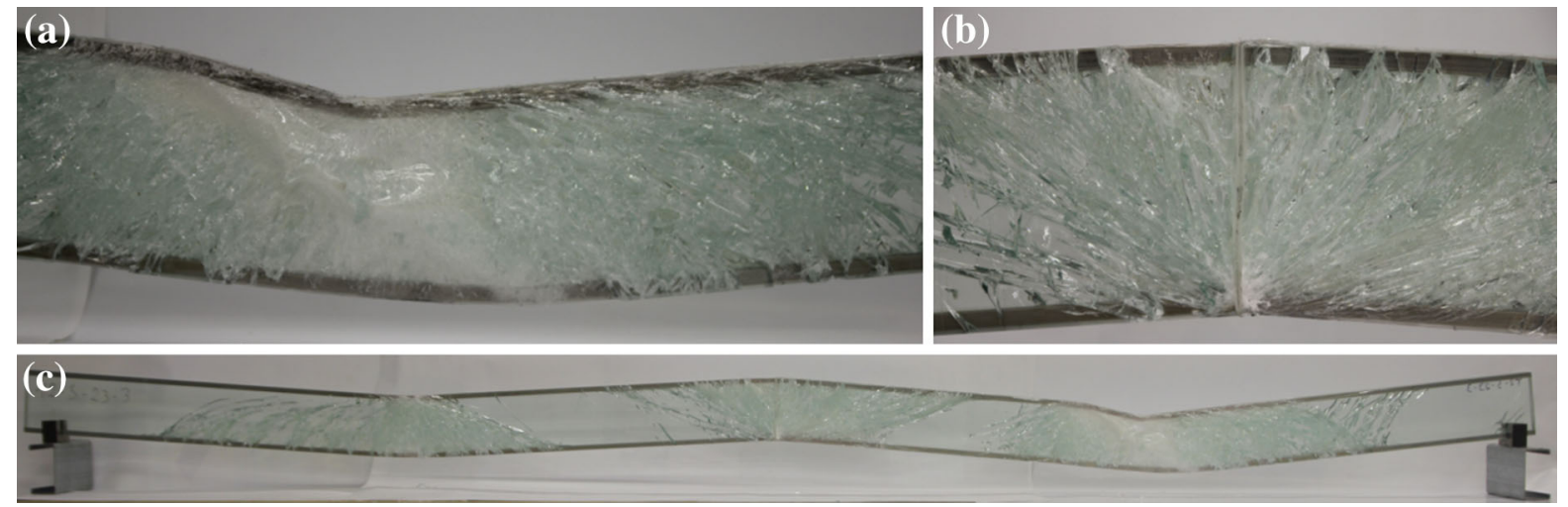

Fig. 8 Pictures of a typical S-23 beam specimen after testing: a Collapsed section, b Central 'connected' section, c Entire beam

\subsubsection{Solid reinforced beam specimens tested at $23^{\circ} \mathrm{C}$}

Starting with the beams S-23, reinforced with solid stainless steel sections and tested at $23^{\circ} \mathrm{C}$, it is stated that this beam illustrated a safe load-carrying behaviour, existing out of four phases. In a first phase, the beam responds linear elastically to the imposed displacement up to a critical load level of about $29 \mathrm{kN}$ at which first glass fracture occurred in one of the span zones (called the 'initial failure load'). This phase is denoted as the linear elastic phase. In a second phase, called the fractured phase, the glass beam could further be loaded while new glass fractures appeared and existing fractures further evolved towards the compressive glass zones. Typically, first fracture was followed by fracture in the other span and then both span zones further fractured. As the central support zone is much weaker (only reinforcement and interlayer sections), the statically indeterminate system redistributed the stresses from central support towards the spans, keeping it intact for a long time until the span zones were fractured so much that the difference in relative weakness became insignificant and any stress redistribution mechanism vanished. From that point, also the central zone started to fracture. These fractures originated from the tensile edge of the beam (not from the central seam). First fractures typically appeared on one side of the seam, immediately followed by fractures at the other side, restoring symmetry. The current phase kept on until the reinforcement sections started to yield at the critical sections, forming plastic hinges. This phase is called the 'plastic phase'. During this phase, the displacement could be increased without significant increase in load (only due to strain hardening). More and more glass fractures entered the compressive zone of the glass up to the point where it collapsed at one of the spans or at the central support. As a result, the compressive glass zone was pulverized and the top reinforcement section was pushed downwards on the intact glass. This phenomenon was characterised by a significant load drop. In this latter phase, a maximum load of $81 \mathrm{kN}$ was reached, called the beam's ultimate capacity. Due to the intact bottom and top reinforcement, a residual load-transfer mechanism (not shown on the graphs) was created. Together with significant load redistribution towards the central support, the beam system was able to withstand a limited but significant residual load in this final phase ('the residual phase'). Increasing the displacement resulted in gradual lateral buckling of the top reinforcement section and interlayer at the collapsed span zone until final collapse of the beam occurred. An illustration of a typical beam after the test is given in Fig. 8. Focusing on the central section, it is stated that the seam opened up at the tensile side of the beam. Hence there is relative rotation between contacting glass panels about the central support, resulting in extra flexibility compared to the tests performed on continuous glass beams (Martens et al. under review).

\subsubsection{Hollow profile reinforced beam specimens tested at $23^{\circ} \mathrm{C}$}

The hollow profile reinforced beams tested at $23^{\circ} \mathrm{C}$ (H-23) exhibited the same three phases as their solid reinforced counterparts. A linear elastic phase was observed until first glass fracture appeared at one of the spans at a load of $19 \mathrm{kN}$. Then, glass fracture further evolved up to the point where the tensile reinforce- 

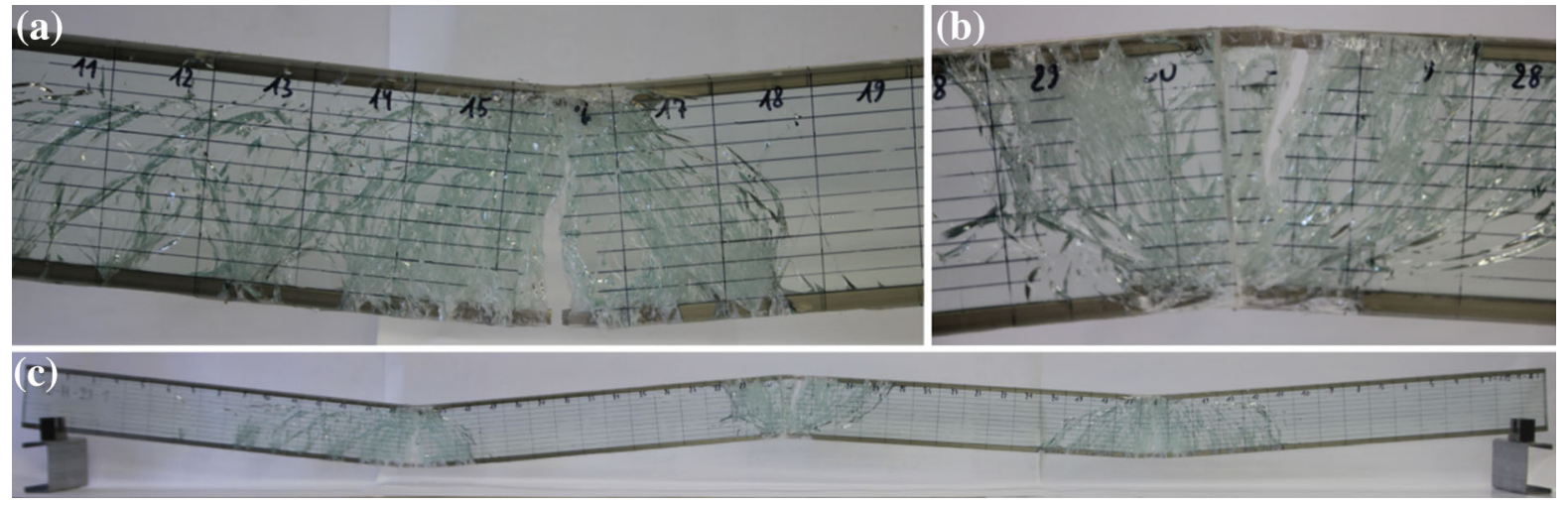

Fig. 9 Pictures of a typical H-23 beam specimen after testing: a Collapsed section, b Central 'connected' section, c Entire beam

ment started to yield. In the plastic phase, all three plastic hinges were formed and the displacement could increase significantly while the critical glass zones further fractured. An average ultimate capacity of about $37 \mathrm{kN}$ was reached. The plastic phase ended due to tensile reinforcement rupture at one of the spans or the central support, resulting in a significant load drop. However, as the compressive reinforcement and glass zone remained intact at the collapsed section, the load could be redistributed to the other intact beam zones, resulting in a residual load-carrying phase. The maximum residual load was dependent on whether reinforcement rupture happened at the central support or at one of the spans. This residual phase ended when tensile reinforcement rupture occurred at one of the remaining intact zones. Fig. 9 illustrates a typical beam after testing. Also in this case, the central seam opened up during the test, proving relative rotation of the glass panes about the central support.

\subsubsection{Solid reinforced beam specimens tested at $60^{\circ} \mathrm{C}$}

At $60^{\circ} \mathrm{C}$, the solid reinforced beam specimens (S-60) did not exhibit a plastic phase. An initial linear elastic phase up to an initial failure load of about $21 \mathrm{kN}$ was observed, followed by a fractured phase with low bending stiffness. When a maximum load of about $60 \mathrm{kN}$ was reached, one of the span critical sections collapsed due to compressive glass failure before the reinforcement started to yield. The glass pulverized and the top reinforcement section was pushed downwards on the remaining intact glass section. A same residual load phase was encountered as for the S-23 beam specimens (i.e. lateral buckling). However, the residual load level was lower and was gradually decreasing until the end of the test. A typical tested beam is depicted in Fig. 10. Focusing on the central zone, the seam opened up again at the tensile side of the beam (slightly more than observed in the former cases). A new observation for this test series was reinforcement slip (see Fig. 11), which was absent for the tests at $23^{\circ} \mathrm{C}$. The reason for the absence of a plastic phase and the latter observation can be attributed to the interlayer. Due to the higher temperature, the stiffness and strength of SG is significantly lower. Hence, less stress can be transferred between the glass panes and between the glass and reinforcement sections. In this case, bond failure between glass and reinforcement occurred, giving rise to reinforcement slip instead of reinforcement yielding. Due to this bond failure, the stress remained concentrated at the compressive glass zone resulting in its early collapse. The slightly larger relative rotation of the glass panes at the central seam is also a consequence of the weaker interlayer, as the latter is less able to hold all glass panes in place compared to the tests at $23^{\circ} \mathrm{C}$.

\subsubsection{Hollow reinforced beam specimens tested at $60^{\circ} \mathrm{C}$}

Finally, the hollow profile reinforced beams were also tested at $60^{\circ} \mathrm{C}(\mathrm{H}-60)$. As can be seen on Fig. 7, unlike their solid reinforced counterparts, these beam specimens did illustrate a significant plastic phase. They went through a linear elastic phase until initial glass fracture was encountered at an average load of $17 \mathrm{kN}$. Subsequently, a typical fractured phase was encountered up to the point when the reinforcement started to yield, forming plastic hinges. In this plastic phase, 


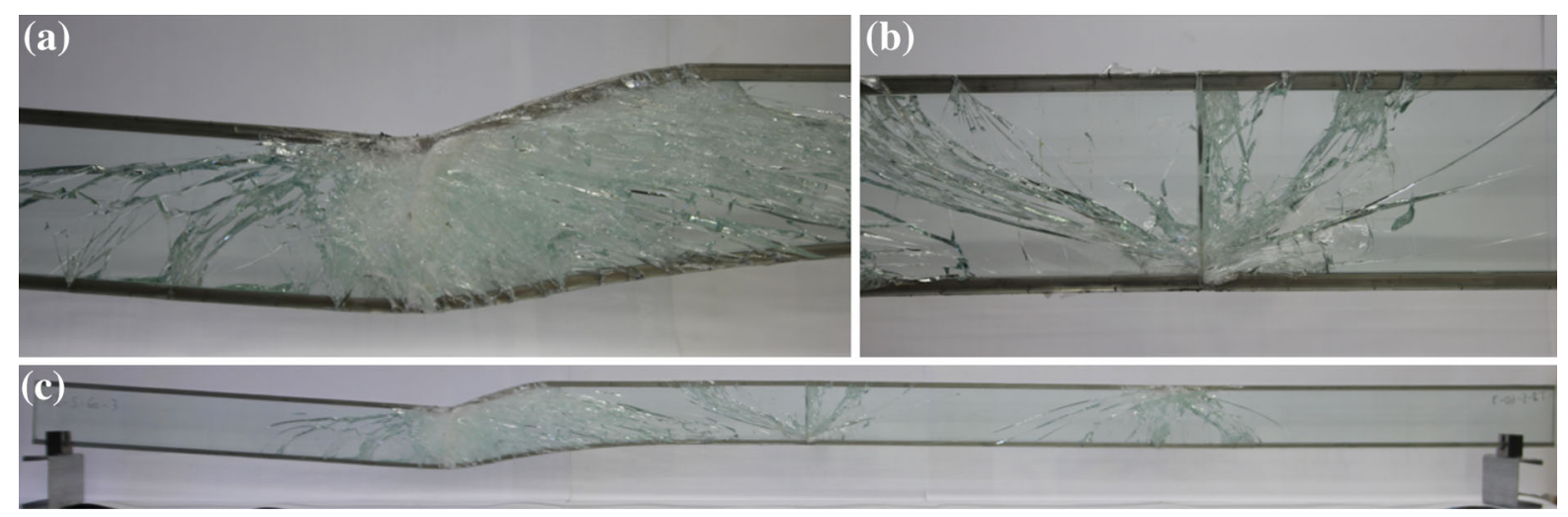

Fig. 10 Pictures of a typical S-60 beam specimen after testing: a Collapsed section, b Central 'connected' section, c Entire beam

Fig. 11 Picture denoting reinforcement slip as observed during the S-60 test series

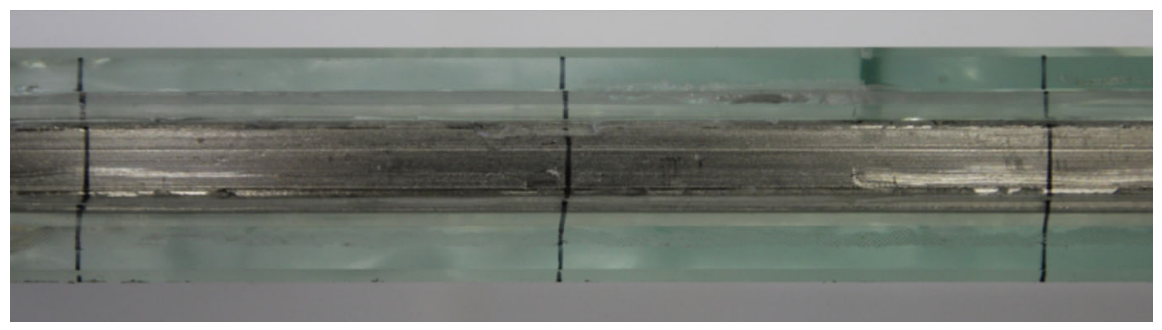

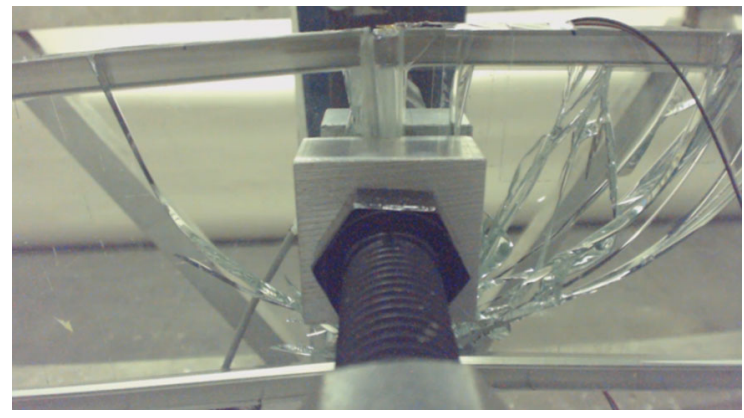

Fig. 12 Snapshot of the opening of the seam during the plastic phase of a typical H-60 beam specimen

a maximum load was encountered of $33 \mathrm{kN}$. Before, but mainly during this phase, the central seam significantly opened up at the tensile side of the beam (see Fig. 12). Hence, significant rotation of the glass panes was encountered for this case. At a displacement of about $50 \mathrm{~mm}$, the tensile reinforcement ruptured at the central support or in one of the span zones, resulting in a significant load drop. As was the case in the H-23 series, the beams were able to install a residual loadcarrying mechanism governed by load redistribution. Also, the residual load level was again dependent on whether the central support zone or one of the spans collapsed first. The residual phase ended with the collapse of the second critical zone, resulting from tensile reinforcement rupture. In Fig. 13, a typical tested beam is depicted. Contrary to the S-60 series, no reinforcement slip was encountered and a plastic phase did occur for the current beams. In this case, the reinforcement section was small enough for the weak interlayer to transfer sufficient stress to make the former yield. This amount of stress is smaller than needed for bond failure. The significant opening of the seam in the plastic phase is attributed to the interlayer, which is able to undergo large elastic deformation at $60^{\circ} \mathrm{C}$.

\subsubsection{Effect of reinforcement percentage and temperature}

As can be concluded from the former, it is clear that reinforcement percentage and temperature independently have a significant influence on the load-carrying behaviour of these 'connected' beam systems. Moreover, some phenomena encountered can be attributed to the combined effect of both parameters.

Reinforcement percentage has a major effect in all four phases of the load-carrying behaviour. In the linear elastic and fractured phases, a smaller reinforcement percentage yields a lower overall bending stiffness due 

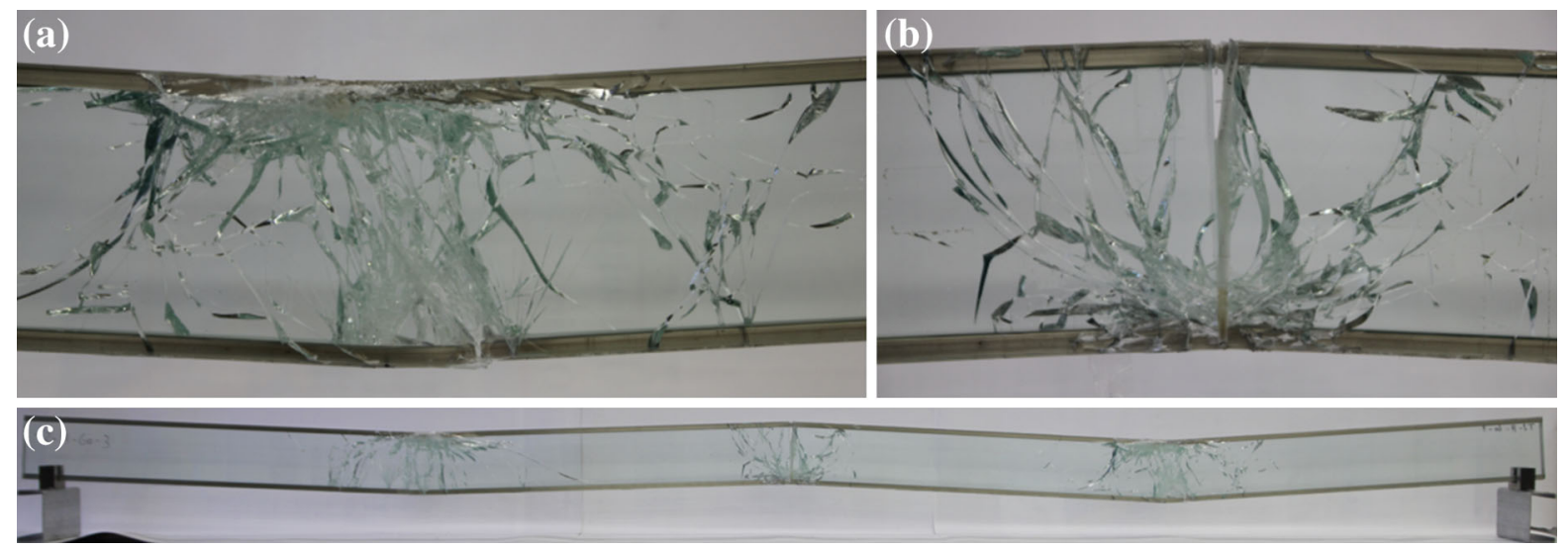

Fig. 13 Pictures of a typical H-60 beam specimen after testing: a Collapsed section, b Central 'connected' section, $\mathbf{c}$ Entire beam

to the lower overall second moment of area. The latter is also the reason for a slightly lower initial failure load. Furthermore, the yield point (the load at which the plastic phase begins) is significantly lower as less load is needed for a smaller section to yield. Furthermore, reinforcement percentage has also an effect on the collapse mechanism. For the cases with solid reinforcement sections, the maximum glass compressive stress was exceeded before the reinforcement started to rupture. In the cases with hollow reinforcement sections, the opposite was true. Of course, the residual phase is directly dependent on the collapse mechanism. In the cases with solid reinforcement sections, the residual phase was characterized by lateral buckling. In cases with hollow reinforcement sections, this phase was characterised by further yielding of the reinforcement and finally the latter's rupture.

Temperature variations primarily affect the mechanical properties of the interlayer. Moreover, since $60^{\circ} \mathrm{C}$ is above the glass transition temperature $\left(55^{\circ} \mathrm{C}\right)$ of $\mathrm{SG}$ at normal humidity, the latter has transformed into a semi-liquid state, resulting in a huge degradation of its stiffness and strength properties. As the interlayer bonds all entities of the beam section, this higher temperature will lower the composite action of the beams. Looking at the graphs of Fig. 7, it is concluded that the above statement has major effects for the load-carrying behaviour. In the linear elastic phase, the initial failure load is typically lower compared to the tests at $23^{\circ} \mathrm{C}$. This is explained by the lower composite action. Due to dimensional inaccuracies (resulting from production), more load is imposed on one pane which is less distributed to the other panes than at $23^{\circ} \mathrm{C}$. Most significant effects are observed in the fractured phase. The bending stiffness is much lower, which is again the result of the weaker interlayer. In the broken glass zones, the interlayer can only distribute limited amounts of stress between glass panes and reinforcement, resulting in an overall lower stiffness. Moreover, the interlayer is also less able to keep the central seam closed, amplifying the lower bending stiffness. Due to the former statements, the yield point is also is also lower when the $\mathrm{H}$ series are compared. Finally, in the plastic phase, a lower maximum load was reached for the beams tested at $60^{\circ} \mathrm{C}$ as they are more flexible at higher temperatures due to the lower composite action. Similar conclusions regarding failure loads and bending stiffness were drawn in Louter et al. (2012a).

Reinforcement slip (i.e. bond failure) can only be explained by the combined effect of reinforcement and temperature. This was only encountered for the S-60 series and led to early beam collapse without a plastic phase. However, the phenomenon was not encountered for the tests with hollow profile reinforcement. From other tests executed by the authors, it is found that the maximum transferable amount of stress from glass to reinforcement is dependent on the reinforcement section, bond area, cohesive and adhesive strength of the interlayer and the latter's stiffness. Two alternative mechanisms will constitute the maximum. According to the first mechanism, the reinforcement section is small enough and the interlayer properties and bond area sufficient to make the reinforcement yield (S-23, $\mathrm{H}-23$ and H-60 cases). For the second mechanism, the reverse is true. The interlayer and/or bond area is insufficient to transfer enough stress for the reinforcement 
section to yield. The reinforcement draws increasing stress, resulting in bond failure and hence reinforcement slip. The local stresses build up in the glass compressive zone, resulting in the latter's collapse when the strength is exceeded.

\subsubsection{Evaluation of the central section}

Despite the opening of the seam (more significantly at $60^{\circ} \mathrm{C}$ ) and its negative effect on the overall bending stiffness and strength values, the section behaved satisfactory in all cases. In three of the four cases, it was able to form a plastic hinge. In the other case, the beams collapsed due to compressive glass failure in one of the spans and therefore has nothing to do with the relative performance of the weaker section compared to the full-strength section. The current test results have proven that although the glass panes were interrupted at a critical zone, the beam system still possessed safe load-carrying behaviour.

\section{Conclusions}

This paper presents experimental test results that take part in a research project to develop a transparent and safe butt connection for the construction of largescale glass beam systems. Statically indeterminate fivepoint bending tests were performed on $3 \mathrm{~m}$ long reinforced laminated glass beams in which the glass panes were interrupted at the centre, creating a local section with only reinforcement and interlayer. In addition, the effects of reinforcement percentage and higher temperature were investigated.

It was concluded that all beam specimens illustrated safe load-carrying behaviour with significant post-fracture performance and ductility. This behaviour could be subdivided into four phases, namely the linear elastic, fractured, plastic and residual phases. Only the solid reinforced beams tested at $60^{\circ} \mathrm{C}$ lacked a plastic phase due to reinforcement slip.

The reinforcement percentage had major influence on the load-carrying behaviour concerning bending stiffness, initial failure load, yield point, ultimate capacity and collapse mechanism. The higher the reinforcement percentage, the higher all strength values and the more the collapse mechanism will shift from reinforcement rupture towards compressive glass failure Similar observations were done by Ølgaard et al.
(2009) and Louter et al. (2012b). Increasing temperature affects the mechanical properties of the interlayer and therefore also the load-carrying behaviour of the beam specimens. The higher the temperature, the lower the initial failure load, bending stiffness in the fracture phase, yield point and ultimate failure load. Furthermore, the higher the temperature, the higher the probability for reinforcement slip and the more the seam opens (i.e. the higher the relative rotation of contacting glass panes at the location of the central support) during the test. Reinforcement percentage and temperature have a combined effect on reinforcement slip. The higher both entities, the higher the probability for reinforcement slip.

The hypothetical connection illustrated satisfying behaviour in all test cases. Despite the opening of the central seam, the central zone was able to form a plastic hinge while retaining its integrity.

Acknowledgments The "Agency for Innovation and Technology in Flanders (IWT)" is gratefully acknowledged for supporting this work (Grant No. 141526).

\section{Compliance with ethical standards}

Conflicts of interest On behalf of all authors, the corresponding author states that there is no conflict of interest.

\section{References}

Callewaert, D.: Stiffness of glass/ionomer laminates in structural applications. PhD thesis, Ghent University, Ghent (2012)

Carvalho, P., Cruz, P.J.S., Veer, F.A.: Perforated Steel Plate to Laminated Glass Adhesive Properties. Glass Performance Days, Tampere (2011)

Carvalho, P., Cruz, P. J. S., Veer, F. A.: Connecting through reinforcement-experimental analysis of the temperature dependent behaviour. COST Action TU0905-Mid-term conference on structural glass, pp. 477-484 (2013)

Louter, P. C., Veer, F.: Large span reinforced glass beams, prototype research. IASS Shell and spatial structures. pp. 1-10 (2007)

Louter, P.C., Belis, J., Veer, F.A., Lebet, J.: Durability of SGlaminated reinforced glass beams: effects of temperature, thermal cycling, humidity and load-duration. Con. Build. Mat. 27(1), 280-292 (2012a). doi:10.1016/j.conbuildmat. 2011.07.046

Louter, P.C., Belis, J., Veer, F.A., Lebet, J.: Structural response of SG-laminated reinforced glass beams: experimental investigations on the effects of glass type, reinforcement percentage and beam size. Eng. Struct. 36, 292-301 (2012b). doi:10.1016/j.engstruct.2011.12.016

Martens, K., Caspeele, R., Belis, J.: Development of Composite glass glass beams - A review. Eng. Struct. (2015a). doi:10. 1016/j.engstruct.2015.07.006 
Martens, K., Caspeele, R., Belis, J.: Development of reinforced and posttensioned glass beams: review of experimental research. ASCE Struct. Eng. (2015b). doi:10.1061/ (ASCE)ST.1943-541X.0001453

Martens, K., Caspeele, R., Belis, J.: Towards statically indeterminate glass beam systems-experimental investigations. (under review at Journal of Construction and Building Materials)

Nijsse, R.: Special steel and adhesively bonded connections for glass structures. Struct. Eng. Int. 2, 104-106 (2004). doi: 10. 2749/101686604777964125

Ølgaard, A.B., Nielsen, J.H., Olesen, J.F.: Design of mechanically reinforced glass beams: modelling and experiments. Struct. Eng. Int. 19(2), 130-136 (2009). doi:10.2749/ 101686609788220169

Puller, K.: Untersuchung des Tragverhaltens von in die Zwischenschicht von Verbundglas integrierten Lasteinleitungselementen. epubli GmbH, Berlin (2012)

Puller, K., Sobek, W.: Load-carrying behaviour of metal inserts embedded in laminated glass. Challenging Glass 3conference on architectural and structural applications of glass. (2012). doi:10.3233/978-1-61499-061-1-307

Ringli, R., Vogel, T.: Load-bearing behavior of spliced glass beams under bending action. Glass Struct. Eng. (2016) doi:10.1007/s40940-016-0006-5
Santarsiero, M., Louter, P. C., Carvalho, P., Cruz, P. J. S.: Experimental and numerical investigations of metal-toglass embedded connections with thin stainless steel plate. COST Action TU0905-Mid-term conference on structural glass, pp. 421-428 (2013)

Santarsiero, M., Louter, P.C.: Preliminary Studies on the Mechanical Behaviour of Thick Embedded Laminated Connections. Glass Performance Days, Tampere (2015)

Snijder, A., Veer, F. A., Nijsse, R., Baardolf, K., Romein, T.: Designing and testing an eight meter span glass portal frame. Engineered Transparency-International conference at glasstec, pp. 163-171 (2014)

Trösch, E., Kassnel-Henneberg, B.: Load-bearing behaviour of splice-laminated glass beams for wide spans. Challenging Glass 4 \& COST Action TU0905 Final Conference, pp. 531-539 (2014)

Valarinho, L., Correia, J. R., Branco, A.: Experimental study on the flexural behaviour of multi-span transparent glassGFRP composite beams. Con. Build. Mat. (2013). doi:10. 1016/j.conbuildmat.2012.11.024

Veer, F.A., Gross, S., Hobbelman, G.J., Vredeling, M., Janssen, M.J.H.C., van den Berg, R., Rijgersberg, H.: Spanning Structrues in Glass. Glass Processing Days, Tampere (2003) 